\title{
Commentary to: Cost of poor adherence to anti-hypertensive therapy in five European countries
}

\author{
Afschin Gandjour ${ }^{1}$
}

Published online: 28 July 2015

(c) Springer-Verlag Berlin Heidelberg 2015

The study by Mennini et al. [1] uses a decision model to assess cost implications of improving adherence to medication in hypertensive patients in five European countries (England, France, Germany, Italy, and Spain) from a payer's perspective over 10 years. To this end, the model predicts the 10-year risk for cardiovascular events based on the Framingham risk equation. In terms of costs, it considers drug and hospitalization costs. The model suggests savings through avoiding cardiovascular events in each of the five countries.

Leaving aside a lack of consideration of costs of (a) medication side effects, (b) outpatient care, (c) rehabilitation, and (d) life extension, this result cannot be replicated based on the input data listed in the publication. This points to a potential lack of internal validity. To explain, consider that the net cost of making one additional patient adherent to blood pressure (BP) medication can be calculated in two steps:

1. Absolute risk reduction of $\mathrm{BP}$ treatment $=$ (probability of $\mathrm{BP}$ control $\mid \mathrm{BP}$ treatment $) \times($ absolute risk reduction|BP control)

2. Net $\operatorname{cost}=10$-year cost of BP treatment - (absolute risk reduction of $\mathrm{BP}$ treatment $) \times(\cos t$ of hospitalization),

where absolute risk reduction (ARR) refers to cardiovascular events. With regard to the first equation, Table 1

This comment refers to the article available at doi:10.1007/s10198-013-0554-4.

Afschin Gandjour a.gandjour@fs.de

1 Frankfurt School of Finance and Management, Sonnemannstr. 9-11, 60314 Frankfurt am Main, Germany provides data on the ARR of BP control. In Italy, for example, a favorable estimate for the ARR of BP control is $5.5 \%(=10-4.5 \%)$, which holds for females. In addition, based on data in Appendix C, $56.7 \%$ of Italian patients treated are controlled. Hence, the ARR of BP treatment is $3.1 \%(5.5 \times 56.7 \%)$. Inserting this value in the second equation yields the net cost: $10 \times € 280-0.031 \times € 3939=$ $€ 2677.16$.

Hence, BP treatment in Italy leads to a net increase in costs. We obtain the same result for the other countries. Therefore, from the reading it is not clear how the authors came up with their finding of savings from adherence improvement. This result is also at odds with the results of cost-effectiveness analyses on BP treatment conducted in England and Germany using the Framingham risk equation as well: they did not show savings except for the treatment of high-risk patients [2, 3].

\section{References}

1. Mennini, F.S., Marcellusi, A., von der Schulenburg, J.M., Gray, A., Levy, P., Sciattella, P., Soro, M., Staffiero, G., Zeidler, J., Maggioni, A., Schmieder, R.E.: Cost of poor adherence to antihypertensive therapy in five European countries. Eur J Health Econ 16(1), 65-72 (2015)

2. Gandjour, A., Stock, S.: A national hypertension treatment program in Germany and its estimated impact on costs, life expectancy, and cost-effectiveness. Health Policy 83(2), 257-267 (2007)

3. Montgomery, A.A., Fahey, T., Ben-Shlomo, Y., Harding, J.: The influence of absolute cardiovascular risk, patient utilities, and costs on the decision to treat hypertension: a Markov decision analysis. J Hypertens 21(9), 1753-1759 (2003) 